\title{
Clinical and Molecular Characters of a Yemeni Child with Wiskott-Aldrich Syndrome
}

\author{
Saeed Thabet ${ }^{1}$, Abdulgafoor Kassim², Nabil Al-Jomaai ${ }^{3}$, Ramea Alathwary ${ }^{4}{ }^{*}$, Saddam Alhalemi $^{5}$ \\ ${ }^{1}$ Hematology, Internal Medicine, Faculty of Medicine, Taiz University, Taiz, Yemen \\ ${ }^{2}$ Gastroenterology and Hepatology, Internal Medicine, Faculty of Medicine, Taiz University, Taiz, Yemen \\ ${ }^{3}$ Pediatric Department, Althawra Hospital, Ibb, Yemen \\ ${ }_{4}^{4}$ Internal Medicine, Internal Medicine Department, Faculty of Medicine, Taiz University, Taiz, Yemen \\ ${ }^{5}$ A Private Clinic, Ibb, Yemen \\ Email: saidesco@gmail.com, a.algafoor@gmail.com,drnabilmy33@gmail.com, ^alathwaryramea@gmail.com, \\ saddamnasralhalemi@yahoo.com
}

How to cite this paper: Thabet, S., Kassim, A., Al-Jomaai, N., Alathwary, R. and Alhalemi, S. (2019) Clinical and Molecular Characters of a Yemeni Child with WiskottAldrich Syndrome. Open Access Library Journal, 6: e5235.

https://doi.org/10.4236/oalib.1105235

Received: February 11, 2019

Accepted: March 17, 2019

Published: March 20, 2019

Copyright $\odot 2019$ by author(s) and Open Access Library Inc.

This work is licensed under the Creative

Commons Attribution International

License (CC BY 4.0).

http://creativecommons.org/licenses/by/4.0/

\section{(c) (i) Open Access}

\begin{abstract}
Wiskott-Aldrich Syndrome is an x-linked immunodeficiency condition characterized by microthrombocytopenia, eczema and recurrent infections. It is caused by mutations in the Wiskott Aldrich Protein (WASP) gene. Hereby we report a 13-month-old Yemeni male infant with mutation in WASP Gene, who presented with congenital microthrombocytopenia, eczema, bleeding tendency and recurrent infections. The variant found in this case creates a shift in the reading frame located in the exon 10 of WAS gene. These variants were also detected in the child's mother in heterozygous state.
\end{abstract}

\section{Subject Areas \\ Internal Medicine}

\section{Keywords}

Wiskott-Aldrich, Microthrombocytopenia, Eczema, Yemen

\section{Introduction}

Wiskott-Aldrich Syndrome is an x-linked immunodeficiency condition characterized by microthrombocytopenia, eczema and recurrent infection [1]. WiskottAldrich Syndrome is due to a mutation in the Wiskott-Aldrich syndrome protein (WASP) Gene [2]. The WASP Gene was discovered in 1994. It comprises 12 exons that encode 502 amino acids [3]. WASP plays an important role in actin cytoskeletal rearrangement widely expressed in hematologic lineage. Absence or 
defective WASP leads to disturbance in cellular and humoral immunity, as well as impaired platelets formation [4]. Mutations in WASP are now known to result in a clinical spectrum which encompasses three clinical forms; classical WAS with the triad of thrombocytopenia, eczema and recurrent infection, X-linked Thrombocytopenia (XLT) which is the milder form and X-linked neutropenia (XLN) without features of classical WAS or XLT [5]. Classical WAS carries the poorest prognosis and currently the only curative therapy is Hematopoietic Stem Cell Transplantation (H.S.C.T) [6] [7]. In Asia various mutations have been discovered in several countries [8] [9]. Herein we describe a Yemeni male infant with a classical Wiskott-Aldrich Syndrome and a variant mutation of WAS gene.

\section{Case Presentation}

A 13-month-old infant was referred to us with a chief complaint of fever, purpuric skin rash, recurrent eczema since infancy. He was the product of full term normal vaginal delivery of an unconsanguineous marriage. He was apparently well until 6 months of age when he has developed eczema over the face, neck, back and trunk, skin purpuric rash, and bleeding from gums and nose. $\mathrm{He}$ visited several doctors in Ibb and Sana'a Cities, where different medications were given but no improvement was noted and no diagnosis was reached. Clinical examination revealed a feverish and anemic infant with upper respiratory tract infection, eczema with scratching marks over his face, purpuric rash spread over legs, and there was mild splenomegaly. The laboratory investigations during 2017 are presented in (Table 1) and showed no significant improvement in hemoglobin level and platelet counts despite transfusions of packed RBC'S and platelets concentrates. Blood film study showed thrombocytopenia with small sized platelets (Figure 1). Bone marrow aspiration showed normal cellularity with presence of megakaryocytes forming small platelets. According to the described clinical manifestations and laboratory data with anemia and thrombocytopenia with small platelets, the diagnosis of Wiskott-Aldrich Syndrome was considered with a recommendations of undergoing genetic analysis for confirmation of the diagnosis. The patient was treated with corticosteroid, intravenous immunoglobulin, broad spectrum antibiotics, and blood transfusion as needed and his parents was advised to go with their child outside our country for further investigations including gene analysis and hematopoietic stem cell transplantation which are not available in Yemen. They went to Saudia Arabia and blood samples from the patient and his mother were sent to Germany (CENTOGEN Gold Laboratory) for genetic analysis. The results confirmed the initial diagnosis of WAS syndrome were a whole exon sequencing showed a variant mutation of WASP Gene; WAS c.1250del p.(Pro417Leuf ${ }^{\star} 28$ ) was located in exon 10 and creates a shift in reading frame starting at code 417 (Figure 2 and Figure 3 ). The new frame ends in a stop codon 27 positions downstream (Figure 3). The mutation analysis of the mother was the same mutation variant found in her child but 
in a heterozygous state (Figure 4). At present the baby still in Saudi Arabia waiting in the list for bone marrow transplantation.

Table 1. Results of hematological parameters of our patient during 2017.

\begin{tabular}{|c|c|c|c|c|}
\hline Date & $\begin{array}{c}\mathrm{Hb} \\
\mathrm{mg} / \mathrm{dl}\end{array}$ & $\begin{array}{c}\mathrm{WBC} \\
\left(\mathrm{cell} / \mathrm{mm}^{3}\right)\end{array}$ & $\begin{array}{l}\text { Platelets count } \\
\quad\left(\text { cell } / \mathrm{mm}^{3}\right)\end{array}$ & $\begin{array}{l}\text { ESR } \\
(\%)\end{array}$ \\
\hline $16 / 03 / 2017$ & 5.9 & 11,600 & 32,000 & - \\
\hline $10 / 04 / 2017$ & 6.1 & 6600 & 6000 & 110 \\
\hline $10 / 04 / 2017$ & 9 & 6680 & 18,000 & - \\
\hline $17 / 04 / 2017$ & 8.5 & 12,000 & 18,000 & 65 \\
\hline $24 / 04 / 2017$ & 7.4 & 4700 & 35,000 & 69 \\
\hline $01 / 05 / 2017$ & 6.5 & 12,900 & 4000 & - \\
\hline 08/05/2017 & 9.6 & 7100 & 4000 & - \\
\hline $15 / 05 / 2017$ & 9 & 9500 & 9000 & - \\
\hline $22 / 05 / 2017$ & 8 & 4200 & 10,000 & 126 \\
\hline $28 / 05 / 2017$ & 7.7 & 4100 & 9000 & - \\
\hline 05/06/2017 & 7.5 & 9500 & 17,000 & 140 \\
\hline $12 / 06 / 2017$ & 7 & 13,600 & 15,000 & 70 \\
\hline 03/07/2017 & 6.7 & 7800 & 11,000 & 121 \\
\hline $13 / 07 / 2017$ & 7.5 & 5700 & 27,000 & 59 \\
\hline $20 / 07 / 2017$ & 8.3 & 6400 & 13,000 & 98 \\
\hline 07/08/2017 & 9.6 & 10,400 & 12,000 & 103 \\
\hline $23 / 10 / 2017$ & 8.2 & 7500 & 10,000 & 81 \\
\hline $26 / 10 / 2017$ & 8 & 6100 & 12,000 & 79 \\
\hline $30 / 10 / 2017$ & 8.7 & 5800 & 10,000 & 120 \\
\hline $23 / 11 / 2017$ & 8 & 11,400 & 12,000 & 129 \\
\hline $30 / 11 / 2017$ & 7.6 & 9000 & 8000 & - \\
\hline
\end{tabular}

$\mathrm{Hb}=$ hemoglobin, $\mathrm{WBCs}=$ White blood cells, $\mathrm{ESR}=$ erythrocyte sedimentation rate.
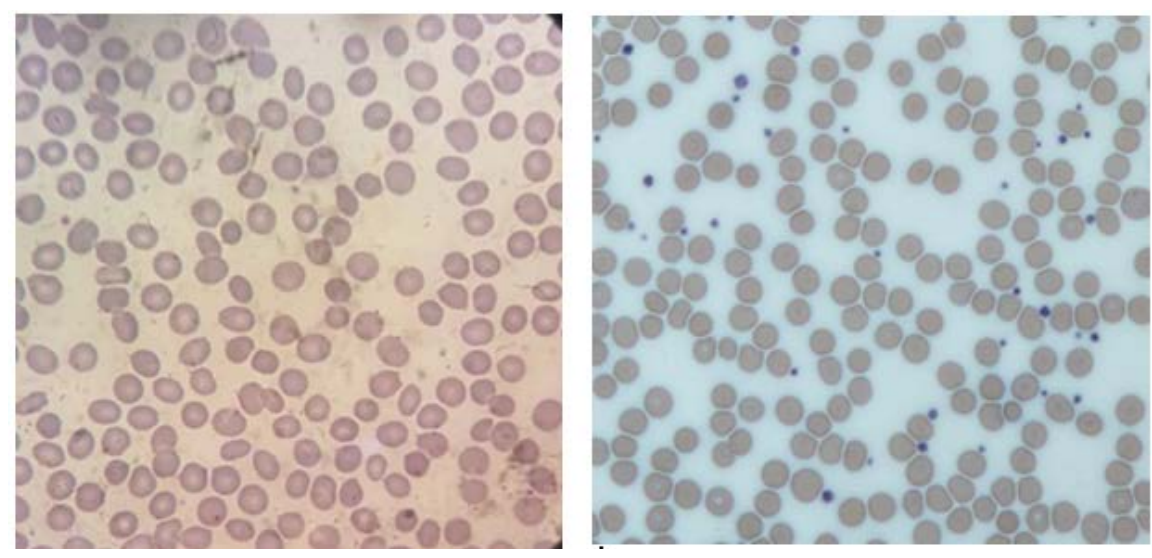

Figure 1. Blood film of our patient in the Left in comparison with normal blood film in the right. 


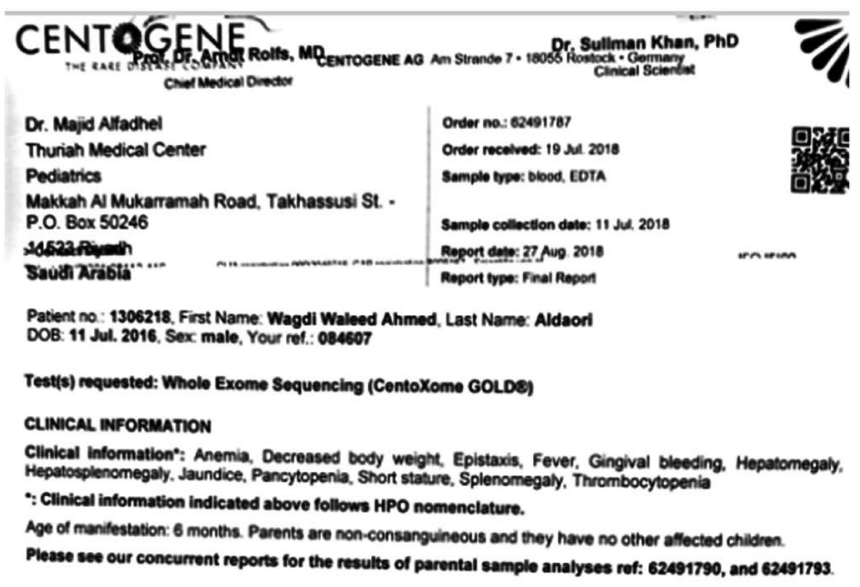

† POSITIVE RESULT

Likely pathogenic variant identified

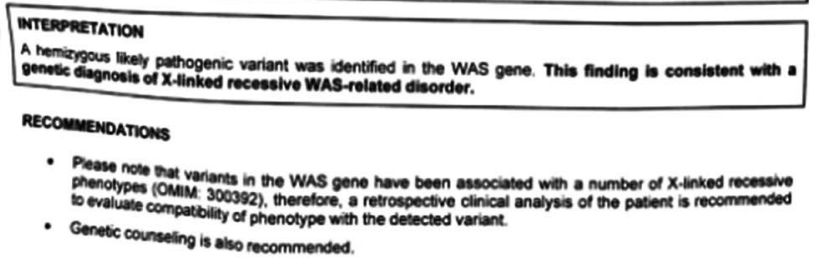

Figure 2. Genetic analysis of the studied infant.

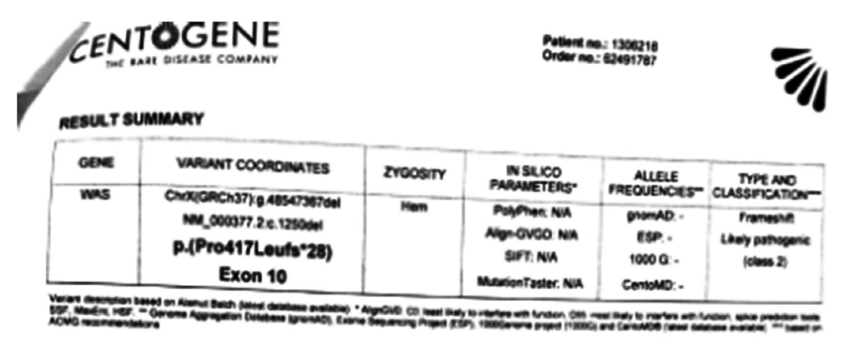

VARUNT INTERPRETATION

WAS, C.1250del P(ProdizLeutseren)

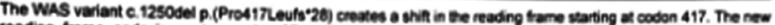

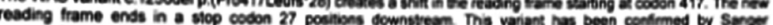

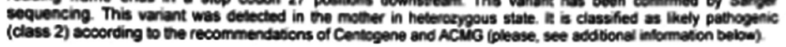

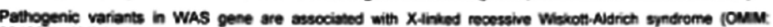

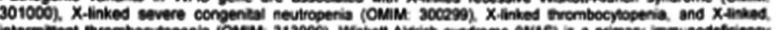

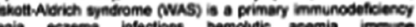

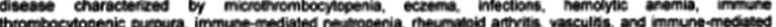
damage to the kidneys and liver (PMID. 20301357). ODer spmptoms may include epistaxis, oral bleeding inflamenatory bowel disease, ent meninglis (OMAlat 301000).

INCIDENTAL FINDINGS We did not defect any class 1 or 2 variants in the genes for mich incidental tindings are reported based on the
ACMGG guidelines.

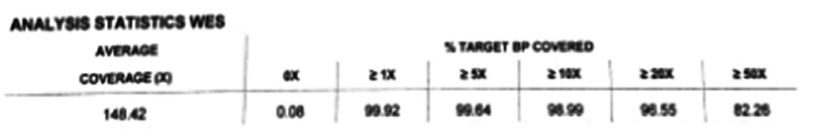

CENTOGENE VARIANT CLASSIFICATION (BASED ON ACMO RECOMMENOATIONS)

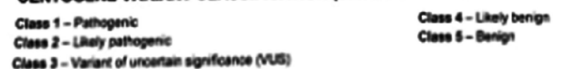

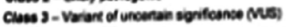

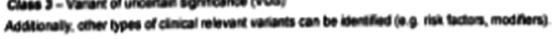

METHOos

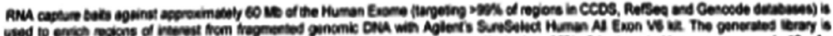

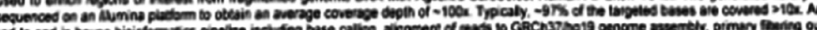

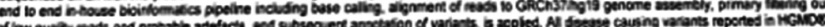

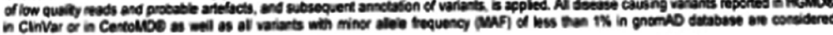

Figure 3. Genetic analysis of the studied infant. 


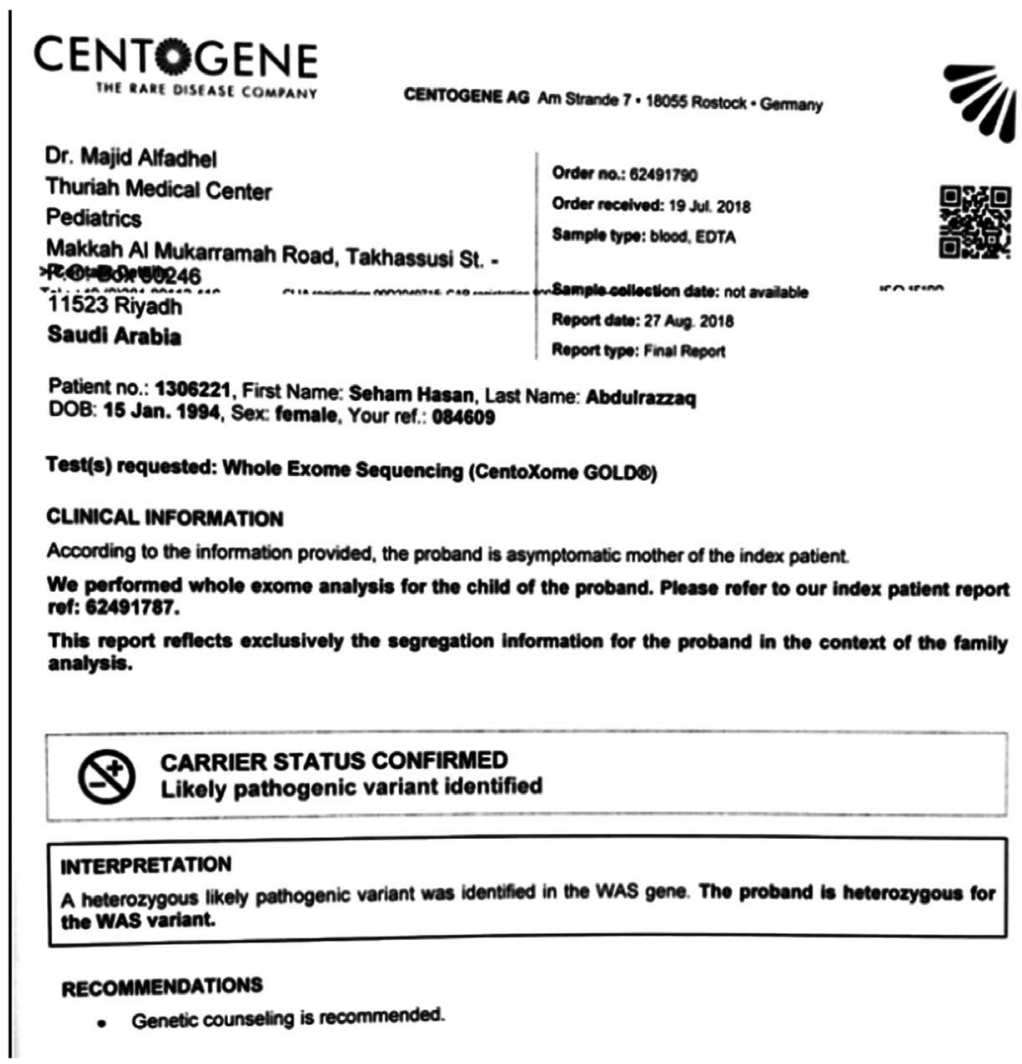

Figure 4. Genetic analysis of the infant's mother.

\section{Discussion}

Wiskott-Aldrich Syndrome varies considerably in severity and is usually manifested in the first weeks or months of life with bleeding tendency due to congenital thrombocytopenia, frequently presented with bloody diarrhea, epistaxis, gingival bleeding or petechial rash of the skin and oral mucosa [10] [11] [12]. Subsequently recurrent bacterial infections develop commonly as upper respiratory tract infection, otitis media, pneumonia etc. [12]. There is also depressed cell mediated immunity with increased risk of viral and fungal infections [13]. Eczema is the most common variable feature and is indistinguishable from atopic dermatitis, with scratching [14]. Later in the course of the disease, other manifestations can be noted such as autoimmune hemolytic anemia, arthritis, nephropathy, and increase incidence of malignancy [14] [15]. Our case demonstrated characteristic clinical triad of Wiskott-Aldrich syndrome in the form of intermittent bleeding because of thrombocytopenia, recurrent infections, and intractable eczema since infancy. Low platelets count and small platelets size seen in blood film clinched the diagnosis in favor of Wiskott-Aldrich syndrome, and the diagnosis was confirmed by genetic study. We directed our treatment mainly to control bleeding through transfusions of blood and platelets, and control of infections with antibiotics and Immunoglobulin replacement and we advised our patient's parents to travel for Hamatopoeitic stem cell Transplantation as cure can only be achieved with it [16]. To the best of our knowledge no pre- 
vious report about Wiskott-Aldrich Syndrome in Yemeni patient, and few reports were published from Saudi Arabia, Lebanon and Syria (Arab Genomic Center) [17]. More than 300 mutations of the WASP have been reported; mainly of missense/nonsense mutations, among various ethnic groups, these mutations have been reported in all 12 exon with the majority involves the first 3 exon [18] [19]. In our patient the mutation was (WAS exon 10, c.1250del p.(Pro417Leufs ${ }^{\star 28}$ ). This mutation resulting in creating new frame shift starting in codon 417 and ends in codon 27 down stream (WAS Variant) resulting in sever clinical presentations in our patient resembling classical Wiskott-Aldrich Syndrome.

\section{Conclusion}

We report the clinical manifestations, laboratory investigations and molecular characterization of a Yemeni child with Wiskott-Aldrich Syndrome. Wiskott-Aldrich Syndrome is a rare condition which needs a high index of suspicion for early diagnosis and should be suspected in any male infant with Eczema, recurrent infection and congenital thrombocytopenia.

\section{Conflicts of Interest}

The authors declare no conflicts of interest regarding the publication of this paper.

\section{References}

[1] Albert, M.H., Bittner, T.C., Nonoyama, S., et al. (2010) X-Linked Thrombocytopenia (XLT) Due to WAS Mutations: Clinical Characteristics, Long-Term Outcome, and Treatment Options. Blood, 115, 3231-3238.

https://doi.org/10.1182/blood-2009-09-239087

[2] Derry, J.M., Ochs, H.D. and Francke, U. (1994) Isolation of a Novel Gene Mutated in Wiskott-Aldrich Syndrome. Cell, 78, 635-644. https://doi.org/10.1016/0092-8674(94)90528-2

[3] Orange, J.S., Stone, K.D., Turvey, S.E. and Krzewski, K. (2004) The Wiskott-Aldrich Syndrome. Cellular and Molecular Life Sciences, 61, 2361-2385. https://doi.org/10.1007/s00018-004-4086-Z

[4] Bouma, G., Burns, S.O. and Thrasher, A.J. (2009) Wiskott-Aldrich Syndrome: Immunodeficiency Resulting from Defective Cell Migration and Impaired Immunostimulatory Activation. Immunobiology, 214, 778-790.

https://doi.org/10.1016/j.imbio.2009.06.009

[5] Thrasher, A.J. (2009) New Insights into the Biology of Wiskott-Aldrich Syndrome (WAS). Hematology. American Society of Hematology. Education Program, 132-138. https://doi.org/10.1182/asheducation-2009.1.132

[6] Imai, K., Morio, T., Zhu, Y., et al. (2004) Clinical Course of Patients with WASP Gene Mutations. Blood, 103, 456-464. https://doi.org/10.1182/blood-2003-05-1480

[7] Ozsahin, H., Cavazzana-Calvo, M., Notarangelo, L.D., et al. (2008) Long-Term Outcome Following Hematopoietic Stem-Cell Transplantation in Wiskott-Aldrich Syndrome: Collaborative Study of the European Society for Immunodeficiencies and European Group for Blood and Marrow Transplantation. Blood, 111, 439-445. https://doi.org/10.1182/blood-2007-03-076679 
[8] Itoh, S., Nonoyama, S., Morio, T., et al. (2000) Mutations of the WASP Gene in 10 Japanese Patients with Wiskott-Aldrich Syndrome and X-Linked Thrombocytopenia. International Journal of Hematology, 71, 79-83.

[9] Harfi, H.A., Al-Malik, S. and Tulba, A. (1992) Wiskott-Aldrich Syndrome. Annuals of Saudi Medicine, 12, 355-361. https://doi.org/10.5144/0256-4947.1992.355

[10] Asherson, G.I. and Webster, A.D.B. (1980) Wiskott-Aldrich Syndrome. In: Diagnosis and Treatment of Immunodeficiency Disease, Blackwell-Scientific, London, 240-248.

[11] Standen, G.R. (1988) Wiskott-Aldrich Syndrome: New Perspective in Pathogenesis and Management. Journal of the Royal College of Physicians of London, 22, 80-83.

[12] Perry, G.S., Schuman, L.M., McHugh, R.B., et al. (1980) The Wiskott-Aldrich Syndrome in the United States and Canada (1892-1979). The Journal of Pediatrics, 97, 72-78. https://doi.org/10.1016/S0022-3476(80)80133-8

[13] Rosen, F.S., Cooper, M.D. and Wedgwood, R.G.P. (1984) The Primary Immunodeficiencies. The New England Journal of Medicine, 311, 300-310. https://doi.org/10.1056/NEJM198408023110506

[14] Jin, Y., Mazza, C., Christie, J.R., et al. (2004) Mutations of the Wiskott-Aldrich Syndrome Protein (WASP): Hotspots, Effect on Transcription, and Translation and Phenotype/Genotype Correlation. Blood, 104, 4010-4019. https://doi.org/10.1182/blood-2003-05-1592

[15] Ochs, H.D. and Thrasher, A.J. (2006) The Wiskott-Aldrich Syndrome. Journal of Allergy and Clinical Immunology, 117, 725-736. https://doi.org/10.1016/j.jaci.2006.02.005

[16] Good, R.A. (1987) Bone Marrow Transplantation for Immunodeficiency Disease. The American Journal of the Medical Sciences, 294, 68-74 https://doi.org/10.1097/00000441-198708000-00002

[17] http://www.cags.org.ae/ctga/details.aspx?id=1983\&pg=200\&se=Latest

[18] Baharin, M.F., Kader Ibrahim, S.B., Yap, S.H., Abdul Manaf, A.M., Mat Ripen, A. and Dhaliwal, J.S. (2015) Molecular Characterization of Two Malaysian Patients with Wiskott-Aldrich Syndrome. Malaysian Journal of Pathology, 37, 153-158.

[19] Zhu, Q., Watanabe, C., Liu, T., et al. (1997) Wiskott-Aldrich Syndrome/X-Linked Thrombocytopenia: WASP Gene Mutations, Protein Expression, and Phenotype. Blood, 90, 2680-2689. 